\title{
Produção de almeirão em função de níveis de fertirrigação nitrogenada e disposição de mangueiras gotejadoras nos canteiros
}

\author{
Chicory yield under levels of nitrogen fertirrigation and position of drip hoses on the ridge
}

\author{
Guilherme Augusto Biscaro ${ }^{\text {I }}$ Janiele Araújo da Silva ${ }^{I I}$ Patricia dos Santos Zomerfeld ${ }^{I I I}$ \\ Anamari Viegas de Araujo Motomiya ${ }^{\text {IV }}$ Eder Pereira Gomes $^{\text {IV }}$ Graziane Maria Giacon $^{\text {III }}$
}

\section{RESUMO}

\begin{abstract}
O objetivo deste trabalho foi avaliar os efeitos de diferentes níveis de fertirrigação nitrogenada na produtividade e nas características agronômicas de plantas de almeirão, irrigadas por gotejamento. $O$ delineamento experimental foi $o$ de blocos casualizados em esquema de parcelas subdivididas, sendo avaliadas nas parcelas duas formas de disposição das mangueiras gotejadoras (superficialmente sobre o solo do canteiro e subsuperficialmente) e nas subparcelas seis doses de nitrogênio: 0, 30, 60, 90, 120 e $150 \mathrm{~kg} \mathrm{ha}^{-1}$. A forma de disposição das mangueiras afetou a produção apenas da massa fresca, com o melhor resultado sendo obtido com a irrigação subsuperficial. A produção e as características agronômicas do almeirão foram influenciadas pelas doses de nitrogênio aplicadas na água de irrigação nas duas formas de disposição das mangueiras nos canteiros. A maior eficiência financeira da adubação foi obtida com a dose de $30 \mathrm{~kg} \mathrm{ha}^{-1}$ de $\mathrm{N}$ nas duas formas de disposição das mangueiras gotejadoras.
\end{abstract}

Palavras-chave: irrigação por gotejamento, ureia, Cichorium intybus.

\section{ABSTRACT}

In this research the objective was to evaluate the effects of different levels nitrogen fertirrigation on yield and agronomic characteristics of chicory plants irrigated by drip.The experimental design was a randomized block in split plot with two ways of using drip hoses on the ridge (on the surface and subsurface of soil) and six levels of nitrogen, 0, 30, $60,90,120$ and $150 \mathrm{~kg} \mathrm{ha}^{-1}$.The hose layout affected the yield fresh weight only with better results obtained with subsurface irrigation. The yield and agronomic characteristics of chicory were influenced by nitrogen levels applied in irrigation water in the two forms of hoses disposition in the beds. The best economic efficiency of fertilization was obtained with $30 \mathrm{~kg} \mathrm{~N}$ $\mathrm{ha}^{-1}$ in both forms of drip hoses disposition.

Key words: drip irrigation, urea, Cichorium intybus.

\section{INTRODUÇÃo}

O almeirão (Cichorium intybus L.), hortaliça folhosa, pertencente à família Asteraceae, tem sua origem provavelmente na Europa Mediterrânea. Segundo FILGUEIRA (2003), esta se diferencia da chicória devido a seu sabor amargo mais evidente e por apresentar folhas mais alongadas, mais estreitas e recobertas por pelos. Embora do ponto de vista nutricional o almeirão seja superior à alface (KHATHOUNIAN, 2001, citado por NOVO et al., 2003) por ser mais calórico e mais rico em proteínas, amido, fibras, cálcio, ferro e vitamina A, é uma das hortaliças menos estudadas no Brasil quanto ao comportamento das cultivares mais comercializadas.

Como o almeirão é uma hortaliça folhosa, a adubação nitrogenada e seu manejo são extremamente importantes para o sucesso da cultura, devendo-se ter informações específicas sobre a melhor dose de

'Programa de Pós-graduação em Agronomia e em Engenharia Agrícola, Faculdade de Ciências Agrárias (FCA), Universidade Federal da Grande Dourados (UFGD), Rod Dourados-Itahum, km 12, CP 5333, 79804-970, Dourados, MS, Brasil. E-mail: guilhermebiscaro@ufgd.edu.br. Autor para corresondência.

IICurso em Engenharia Agrícola, FCA, UFGD, Dourados, MS, Brasil.

${ }^{\text {IIIC }}$ urso em Agronomia, FCA, UFGD, Dourados, MS, Brasil.

IVPrograma de Pós-graduação em Engenharia Agrícola, FCA, UFGD, Dourados, MS, Brasil. 
nitrogênio a ser utilizada (STEINER et al., 2010). Ainda segundo esses autores, um dos poucos trabalhos de pesquisa, para as condições brasileiras, que abordaram o comportamento do almeirão 'Folha Larga' em relação à nutrição mineral em condições de campo, foi realizado no ano de 1988 por HAAG \& MINAMI.

A fertirrigação é o mais econômico e eficiente método de aplicação de fertilizantes, especialmente quando utilizado por meiode sistemas de irrigação localizada (BURT et al., 1995). A fertirrigação assegura que os fertilizantes sejam aplicados diretamente na região de maior concentração de raízes das plantas, permitindo o fracionamento das doses e o aumento na eficiência da adubação. BURT et al. (1995), quando compararam a fertirrigação por gotejamento com a aplicação de fertilizantes pelo método convencional, observaram um aumento na eficiência de aproveitamento de nutrientes no primeiro método, despendendo-se 20 a $50 \%$ menos fertilizantes que com o método convencional.

A fertirrigação pode ser realizada ainda por meio de gotejamento subsuperficial. A irrigação por gotejamento subsuperficial é uma variação da tradicional irrigação por gotejamento, onde os tubos e emissores são enterrados, diminuindo as perdas por evaporação da superfície do solo, podendo reduzir o consumo de água em até 50\% (AYARS et al., 1999).

Com este trabalho, objetivou-se avaliar a produtividade e o comportamento de características agronômicas de almeirão, submetidas a diferentes níveis de fertirrigação nitrogenada e duas formas de disposição das mangueiras nos canteiros, em condições de campo na Região de Dourados, Mato Grosso do Sul.

\section{MATERIAL E MÉTODOS}

O experimento foi conduzido em Dourados (MS), na Universidade Federal da Grande Dourados, entre 13 de outubroe 22 de dezembro de 2010. A altitude média local é de $446 \mathrm{~m}$, com latitude de $22^{\circ} 11^{\prime} 45^{\prime \prime} \mathrm{S}$ e longitude $54^{\circ} 55^{\prime} 18^{\prime \prime} \mathrm{W}$. Utilizou-se a variedade de almeirão Spadona folhas verdes Radiche, da Empresa Feltrin ${ }^{\circledR}$ Sementes. As sementes foram tratadas com $0,15 \%$ de captan (Captan 75) e colocadas em bandejas de isopor de 128 células. O solo da área experimental foi classificado como Latossolo Vermelho distroférrico (EMBRAPA, 2006). A análise química do solo, coletado antes da instalação do experimento, revelou as seguintes características: $\mathrm{pH} \mathrm{em} \mathrm{CaCl} 2: 5,0 ; 1,0 \mathrm{mg} \mathrm{dm}^{-3}$ de P; 27,5 $\mathrm{g} \mathrm{dm}^{-3}$ de MO; 5,2; 0,6; 41,0; 25,0; 55,0; $126,2 \mathrm{mmolc} \mathrm{dm}^{-3}$ de K, Al, Ca, Mg, H+Al, CTC; 19,8; 62,$6 ; 94,6 ; 2,2 \mathrm{mg} \mathrm{dm}^{-3}$ de $\mathrm{Cu}, \mathrm{Mn}, \mathrm{Fe}, \mathrm{Zn}$, respectivamente, e $56 \%$ de saturação por bases. O solo foi gradeado e encanteirado cerca de 20 dias antes do transplante das mudas, sendo realizada a adubação de base (de acordo com a recomendação da cultura e da análise de solo) com $6,7 \mathrm{~g} \mathrm{~m}^{-2}$ de ureia, $55,6 \mathrm{~g} \mathrm{~m}^{-2} \mathrm{de}$ superfosfato simples e $3,0 \mathrm{~g} \mathrm{~m}^{-2} \mathrm{de} \mathrm{KCl}$. Foram aplicados $5,0 \mathrm{~kg} \mathrm{~m}^{-2}$ de esterco bovino curtido. Os canteiros de cada parcela experimental possuíam 3,0 metros de comprimento e 1,0m de largura.

O sistema de irrigação utilizado foi o localizado, do tipo gotejamento, da marca Petroísa, modelo Manari, com mangueiras espaçadas de $30 \mathrm{~cm}$ entre si e gotejadores espaçados de $20 \mathrm{~cm}$. As mangueiras do sistema subsuperficial foram enterradas uma semana antes do transplante das mudas, a uma profundidade de $15 \mathrm{~cm}$. O transplante das mudas foi realizado aos 30 dias após a semeadura (DAS). O manejo da irrigação foi realizado com base na metodologia sugerida por BERNARDO et al. (2005), por meio de um balanço hídrico e da evapotranspiração, sendo que o tempo de irrigação foi calculado com base na evapotranspiração de cultura, do Kc da fase em que ela se encontrava, na equação de vazão do gotejador (que, no caso, era q=0,463 x $\mathrm{P}^{0,503}$, em que q é a vazão em litros por hora e Pé a pressão de serviço em mca) e no espaçamento entre linhas gotejadoras e emissores.

Considerando a redução das perdas por evaporação, nos tratamentos em que as mangueiras foram dispostas subsuperficialmente nos canteiros, adotou-se um tempo de irrigação correspondente a $75 \%$ do tempo utilizado nas mangueiras dispostas superficialmente.

O delineamento experimental empregado foi o de blocos completos ao acaso em parcelas subdivididas, com quatro repetições. Nas parcelas, foram analisadas duas formas de disposição das mangueiras nos canteiros: enterradas (subsuperficial) e não enterradas (superficial). Nas subparcelas, foram aplicadas seis doses de nitrogênio: 0; 30; 60; 90; $120 \mathrm{e}$ $150 \mathrm{~g} \mathrm{~m}^{-2} \mathrm{de} \mathrm{N}$ na forma de ureia. Cada subparcela foi constituída por 30 plantas, sendo úteis as dez plantas centrais. O transplante das mudas foi realizado aos 30 dias após a semeadura (DAS). Foram realizadas três fertirrigações, correspondentes ao parcelamento das doses ( $1 / 3$ da dose proposta em cada tratamento), aos 14,20 e 31 dias após o transplante (DAT). Todos os tratamentos receberam, também por fertirrigação, $30 \mathrm{~g}$ $\mathrm{m}^{-2} \mathrm{de} \mathrm{KCl}$. Para a injeção dos fertilizantes, foi utilizado um sistema baseado no modelo dos tanques pressurizados, do tipo vaquinha, (processo sob patente), na forma de Modelo de Utilidade (MU).

Aos 38 dias após o transplante (DAT), realizou-se a determinação do índice de clorofila das 
folhas (IC), por meio da leitura com um clorofilômetro SPAD-502, Minolta, o qual calcula o índice de clorofila pela razão entre dois comprimentos de onda transmitidos a $650 \mathrm{~nm}$ (vermelho) e $940 \mathrm{~nm}$ (infravermelho próximo). As leituras foram realizadas no terço médio da segunda folha inferior de dez plantas de almeirão. Após a leitura do índice de clorofila, foi realizada a colheita da parte aérea das plantas das parcelas, para avaliação das seguintes variáveis: número de folhas, comprimento das folhas $(\mathrm{cm})$, largura das folhas $(\mathrm{cm})$, massa fresca das folhas $(\mathrm{g})$ e massa seca das folhas $(\mathrm{g})$.

Após a determinação da massa fresca das folhas, as amostras foram acondicionadas em sacos de papel etiquetados e colocadas para secar em estufa com circulação forçada de ar a uma temperatura de $65^{\circ} \mathrm{C}$ por 72 horas, até que atingissem massas constantes. Com auxílio de uma balança analítica de precisão $(0,01 \mathrm{~g})$, foram determinadas as suas massas e o resultado foi expresso em gramas por planta. Para as análises estatísticas, utilizou-se o programa SAS (2008). O efeito dos tratamentos e da relação entre as variáveis foi avaliado por meio de análise de variância, verificando-se a significância pelo teste F. Quando significativos (5\%), os dados referentes às doses de $\mathrm{N}$ foram submetidos à análise de regressão pelo método dos mínimos quadrados (BANZATO \& KRONKA, 1992).

$O$ custo da energia foi estimado com a seguinte equação: $\mathrm{CE}=0,736$ x PMB x PE x TI x N(01), em que: $\mathrm{CE}=$ custo da energia $\left(\mathrm{R} \$\right.$ ha $\left.^{-1}\right) ; \mathrm{PMB}=$ potência útil do conjunto motobomba $\left(\mathrm{cv} \mathrm{ha}^{-1}\right) ; \mathrm{PE}=$ preço da energia $\left(\mathrm{R} \$ \mathrm{kWh}^{-1}\right)$; $\mathrm{TI}=$ tempo irrigação em horas e $\mathrm{N}$ = número de unidades operacionais. A potência útil foi estimada a partir da seguinte expressão: $P M B=\frac{Q \cdot H}{75 \cdot \eta}(02)$, em que: $\mathrm{Q}=$ vazão da unidade operacional $\left(\mathrm{L} \mathrm{s}^{-1}\right) ; \mathrm{H}=$ altura manométrica (mca) e $\eta=$ rendimento (decimal). A vazão da unidade operacional foi estimada da seguinte

forma: $Q=\frac{Q p \cdot A u}{A p \cdot N \cdot 3600}(03)$, em que: $\mathrm{Qp}=$ vazão da parcela $\left(\mathrm{Lh}^{-1}\right) ; \mathrm{Au}=$ área útil $\left(\mathrm{m}^{2}\right) ; \mathrm{Ap}=$ área da parcela $\left(\mathrm{m}^{2}\right)$ e $\mathrm{N}=$ número de unidades operacionais. Considerou-se o preço de energia (PE) conforme a tarifa B2 rural da Empresa Energética do Mato Grosso do Sul (ENERSUL), com valor igual a $\mathrm{R} \$ 0,23 \mathrm{~kW} \mathrm{~h}^{-1}$. Por se tratar de cultivo na forma de canteiros, considerou-se uma área útil total $(\mathrm{Au})$ de $7000 \mathrm{~m}^{2} \mathrm{ha}^{-1}$. Com objetivo de economizar energia, duas unidades operacionais $(\mathrm{N})$ foram utilizadas. A partir da equação do emissor e da disposição dos tubogotejadores sobre os canteiros, estimou-se uma vazão por parcela (Qp) igual a $51,3 \mathrm{~L} \mathrm{~h}^{-1}$.
Cada parcela continha área útil de $3 \mathrm{~m}^{2}$. Durante os eventos de irrigação, a altura manométrica $(\mathrm{H})$ no início da área experimental foi mantida em $6 \mathrm{~m}$.c.a. Adotou-se um conjunto motobomba com rendimento $(\eta)$ de $60 \%$.

A análise financeira foi realizada por meio das metodologias propostas por HOJI (2007) e o cálculo da eficiência financeira utilizando a equação apresentada por GITMAN (2004), na qual a eficiência financeira é a razão entre a receita obtida e o custo do fertilizante.

\section{RESULTADOS E DISCUSSÃO}

As doses de nitrogênio aplicadas na água de irrigação apresentaram efeitos significativos nas principais características agronômicas do almeirão nas duas formas de disposição das mangueiras nos canteiros, resultando em plantas com maior teor de clorofila, massa fresca e seca da parte aérea. O peso da matéria fresca apresentou resposta significativa em relação à disposição das mangueiras nos canteiros, sendo que o peso médio da parte aérea nos canteiros que receberam irrigação subsuperficial foi de 136,06g, contra 119,42g nos canteiros com irrigação superficial. As demais variáveis analisadas não apresentaram resposta às formas de disposição das mangueiras. Como a água e os nutrientes são fornecidos diretamente ao sistema radicular, não ocorrem perdas devido à evaporação de água e tampouco à volatilização de nutrientes, quando expostos às condições de temperatura e radiação que incidem sobre o solo dos canteiros. Dessa forma, tanto a água quanto os nutrientes são mais eficientemente aproveitados pela planta. Assim, obtém-se uma economia de água aplicada e energia utilizada no sistema de bombeamento.

As características número de folhas $(\mathrm{NF})$ e largura das folhas (L) não apresentaram respostas significativas às doses testadas ou à disposição das mangueiras. NOVO et al. (2003), avaliando o desempenho de três cultivares de almeirão sob cultivo protegido, também não encontraram diferenças em relação ao número de folhas. As doses de $\mathrm{N}$ apresentaram efeitos altamente significativos pelo teste F sobre o teor de clorofila das plantas, medido pelo índice SPAD, para ambas as formas de disposição das mangueiras (Figura 1). Houve interação significativa entre as doses de $\mathrm{N}$ e a disposição das mangueiras sobre esta variável. Fazendo-se o desdobramento da interação, observou-se que o efeito das formas de disposição das mangueiras foi significativo apenas nas doses $0 \mathrm{~kg} \mathrm{ha}^{-1} \mathrm{de} \mathrm{N}$ e $30 \mathrm{~kg} \mathrm{ha}^{-1} \mathrm{de} \mathrm{N}$, não apresentando diferenças entre as formas nas demais doses. 


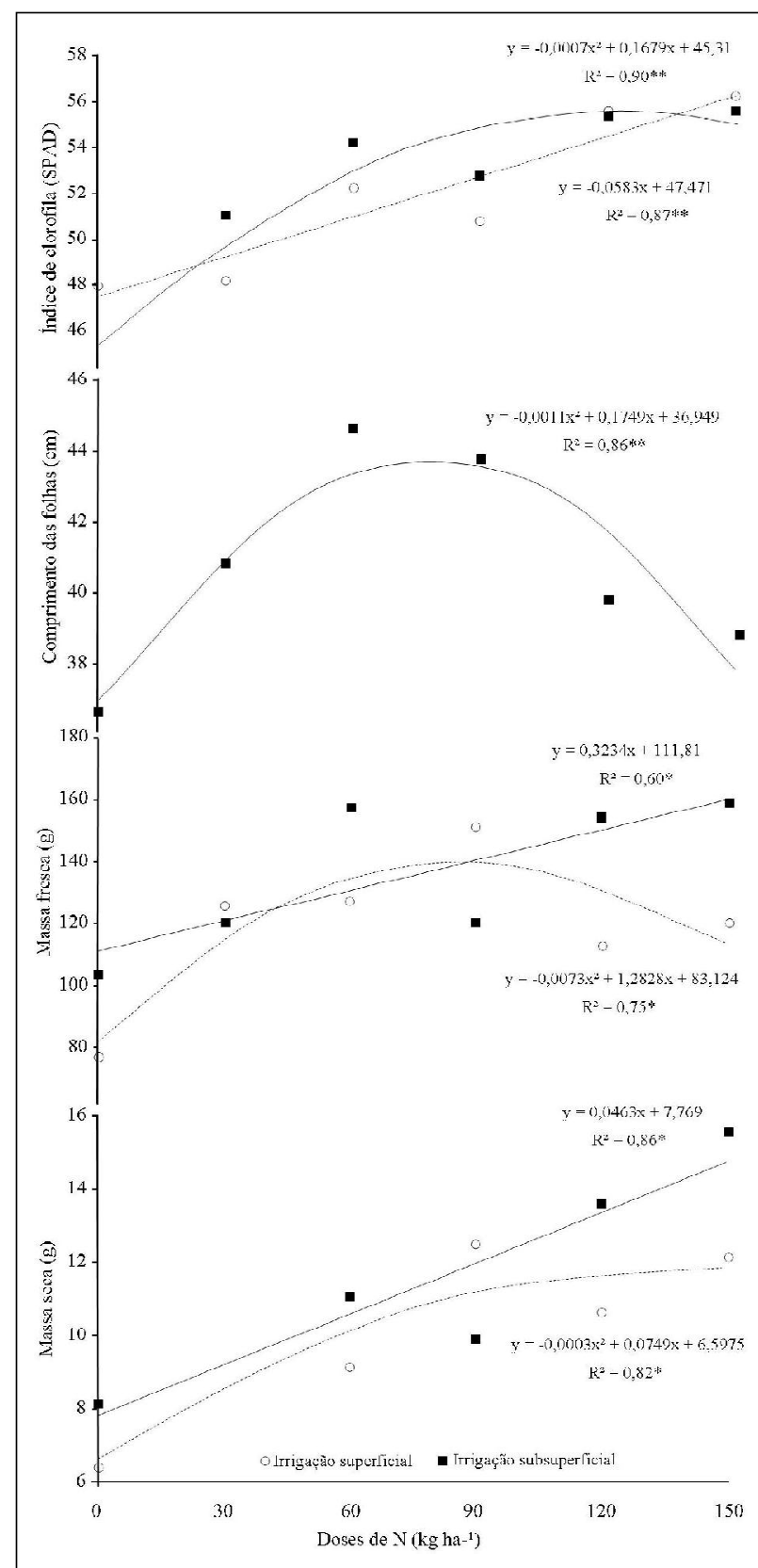

Figura 1 - Índice de clorofila (Spad), comprimento das folhas $(\mathrm{cm})$, massa fresca e massa seca $(\mathrm{g})$ do almeirão submetido a diferentes doses de nitrogênio $(\mathrm{N})$ em duas formas de disposição das mangueiras nos canteiros. Dourados, MS, 2011.

A resposta das culturas à aplicação de nitrogênio é fortemente dependente do suprimento de água durante o desenvolvimento das plantas (HAVLIN et al., 2005). Conforme relataram READ et al. (2002), com a deficiência de $\mathrm{N}$, ocorre diminuição da concentração de clorofila e do conteúdo de proteína solúvel, da taxa de expansão foliar, e também do desenvolvimento da planta. Nesse sentido, observouse que, nos canteiros que utilizaram a irrigação subsuperficial, o teor de clorofila das folhas de almeirão apresentou uma resposta quadrática às doses de $\mathrm{N}$ aplicadas, obtendo-se a maior eficiência técnica na dose de $120 \mathrm{~kg} \mathrm{ha}^{-1}$ de $\mathrm{N}$ na água de irrigação. Isso pode indicar que houve saturação ou "consumo de luxo" de $\mathrm{N}$ pelas plantas, nos tratamentos com doses mais elevadas, uma vez que o $\mathrm{N}$ aplicado não foi incorporado às moléculas de clorofila. SCHRÖDER et al. (2000) ressaltaram que as leituras do clorofilômetro não são boas preditoras do excesso de $\mathrm{N}$, porque, quando a disponibilidade de $\mathrm{N}$ é alta, nem todo o $\mathrm{N}$ é convertido em clorofila.

Utilizando-se a irrigação superficial, observou-se uma resposta linear, obtendo-se o valor máximo de clorofila na maior dose proposta $\left(150 \mathrm{~kg} \mathrm{ha}^{-1}\right)$. Como esta variável está diretamente ligada à quantidade de nitrogênio absorvida pela planta, essa resposta para ambos as formas de irrigação indica que a fertirrigação realmente apresentou efeito significativo nas plantas. As doses de $\mathrm{N}$ apresentaram efeito significativo sobre o comprimento das folhas de almeirão apenas para os tratamentos que utilizaram a irrigação superficial (Figura 1).

Observou-se uma resposta linear para os valores de massa fresca (Figura 1) nos tratamentos que utilizaram o sistema de irrigação localizada subsuperficialmente no canteiro. Já para os tratamentos que utilizaram o sistema de irrigação superficial, encontrou-se uma resposta quadrática, sendo de aproximadamente $90 \mathrm{~kg} \mathrm{ha}^{-1}$ de $\mathrm{N}$ a dose de maior eficiência técnica. MANTOVANI et al. (2005) observaram efeito quadrático da adubação nitrogenada na produção de matéria fresca da parte aérea de cinco cultivares de alface em condições de casa de vegetação e concluíram que, aproximadamente, $60 \mathrm{~kg} \mathrm{ha}^{-1} \mathrm{de} \mathrm{N}$ foi a dose mais adequada para o cultivo de alface em ambiente protegido, pois doses maiores não refletiram em ganho de produção e favoreceram o acúmulo de nitrato na parte aérea. Observou-se um comportamento semelhante para os valores de massa seca (Figura 1), obtendo-se uma resposta linear nos tratamentos que utilizaram o sistema de irrigação localizada subsuperficialmente no canteiro, com valor máximo também para a maior dose proposta, e uma resposta quadrática para os tratamentos que utilizaram o sistema de irrigação superficial, sendo de aproximadamente $125 \mathrm{~kg}$ $\mathrm{ha}^{-1}$ de nitrogênio a dose de maior eficiência técnica.

Analisando o efeito da adubação nitrogenada em duas cultivares de almeirão, em cultivo protegido, STEINER et al. (2010) observaram que as doses de nitrogênio influenciaram significativamente a produção de matéria fresca e matéria seca. Esses 
autores concluíram que, nessa condição de cultivo, a produção respondeu a doses que variaram entre 83 a $108 \mathrm{mg} \mathrm{dm}^{-3}$ (166 a 216kg ha ${ }^{-1}$ ). Considerando o comportamento linear dos tratamentos que utilizaram a irrigação localizada subsuperficialmente, esses valores seriam possíveis de ser obtidos. Porém, para a irrigação superficial (resposta quadrática às doses) essas doses acarretariam em um decréscimo acentuado da produção.

As produções de massa fresca e massa seca máximas, para os tratamentos que possuíam as mangueiras gotejadoras instaladas subsuperficialmente nos canteiros, foram, respectivamente, de 160,3 e 14,7 gramas por planta, ambas obtidas com a dose máxima proposta de $150 \mathrm{~g} \mathrm{ha}^{-1}$ de nitrogênio. Para os tratamentos cujas mangueiras gotejadoras foram dispostas superficialmente, a produção de massa fresca e massa seca foi, respectivamente, de 139,5 e 11,27g por planta. STEINER et al. (2010), estudando a produção das cultivares de almeirão 'Cabeça Vermelha' e 'Folha Larga', verificaram uma produção máxima de massa fresca de 121,4 e 103,4g por planta, respectivamente. Para a massa fresca e massa seca, os tratamentos irrigados superficialmente apresentaram a maior eficiência técnica, utilizando doses que variaram de aproximadamente 90 a $125 \mathrm{~kg} \mathrm{ha}^{-1}$ de nitrogênio. No entanto, a irrigação subsuperficial, associada a doses crescentes de $\mathrm{N}$, proporcionou aumento linear da massa fresca, que representa a principal característica comercial do almeirão.

Durante o experimento, foram realizados nove eventos de irrigação, aplicando lâminas de água iguais a 79,2 e 56,7mm nos sistemas superficial e subsuperficial, respectivamente, o que corresponde a 4,6 e 3,3 horas de irrigação. Utilizando-se das equações 1,2 e 3 , os custos da irrigação nos sistemas superficial e subsuperficial correspondem aos valores de $\mathrm{R} \$ 3,42$ e $\mathrm{R} \$ 2,46$, respectivamente. Do ponto de vista econômico, a irrigação subsuperficial obteve uma economia de energia de apenas $\mathrm{R} \$ 0,96 \mathrm{ha}^{-1}$. No sistema subsuperficial, utilizou-se $225 \mathrm{~m}^{3}$ ha $^{-1}$ de água a menos que no sistema superficial. Segundo TEIXEIRA et al. (2011), ainda que o aumento da eficiência dos fertilizantes seja importante para minimizar o impacto ambiental da atividade agrícola, do ponto de vista dos produtores, este incremento torna-se mais atraente se apresentar algum retorno econômico.

Realizando-se a análise financeira dos dados de produtividade (Tabela 1), de acordo com a dose de ureia aplicada, determinou-se a dose e a forma de aplicação economicamente viáveis. Como o percentual do custo de energia sobre o custo de produção foi muito baixo, este foi desconsiderado. Considerou-se o preço da ureia $(45 \%$ de $\mathrm{N})$ a US $\$ 0,552$ por $\mathrm{kg}$; para se determinar a renda do almeirão, foram utilizados os critérios apontados por SALVADOR et al. (2004), o quais avaliaram a produção e a renda bruta da cebolinha e do almeirão, em cultivo solteiro e consorciado, e chegaram a um valor médio de peso de um maço de almeirão de $230 \mathrm{~g}$. A massa fresca média do pé de almeirão observado neste experimento foi de $136,07 \mathrm{~g}$ nos tratamentos que utilizaram a mangueira gotejadora, disposta subsuperficialmente nos canteiros e de $119,42 \mathrm{~g}$ nos tratamentos que utilizaram a outra forma

Tabela 1 - Análise de eficiência financeira da fertirrigação nitrogenada na cultura do almeirão. Dourados (MS), 2011.

\begin{tabular}{|c|c|c|c|c|c|c|c|c|}
\hline Dose & DMC & $\begin{array}{c}\text { PPA } \\
\text { g planta }^{-1}\end{array}$ & $\begin{array}{c}\text { PTH } \\
\text { g hectare }^{-1}\end{array}$ & QM230 & -------------- & ----------- & M & $\mathrm{EF}$ \\
\hline 0 & sub & 103,75 & 11527777,66 & 50120,77 & $\$ 45.359,30$ & $\$ 0,00$ & $0,00 \%$ & 0,00 \\
\hline 30 & sub & 121,04 & 13448333,20 & 58471,01 & $\$ 52.916,27$ & $\$ 24,01$ & $4,54 \%$ & 2203,74 \\
\hline 60 & sub & 157,66 & 17517777,60 & 76164,25 & $\$ 68.928,65$ & $\$ 48,02$ & $6,97 \%$ & 1435,30 \\
\hline 90 & sub & 120,43 & 13380555,42 & 58176,33 & $\$ 52.649,58$ & $\$ 72,04$ & $13,68 \%$ & 730,88 \\
\hline 120 & sub & 154,48 & 17164444,27 & 74628,02 & $\$ 67.538,36$ & $\$ 96,05$ & $14,22 \%$ & 703,17 \\
\hline 150 & sub & 159,05 & 17672222,05 & 76835,75 & $\$ 69.536,35$ & $\$ 120,06$ & $17,27 \%$ & 579,18 \\
\hline 0 & sup & 77,38 & 8597777,69 & 37381,64 & $\$ 33.830,39$ & $\$ 0,00$ & $0,00 \%$ & 0,00 \\
\hline 30 & sup & 125,91 & 13989444,30 & 60823,67 & $\$ 55.045,42$ & $\$ 24,01$ & $4,36 \%$ & 2292,41 \\
\hline 60 & sup & 127,58 & 14175555,41 & 61632,85 & $\$ 55.777,73$ & $\$ 48,02$ & $8,61 \%$ & 1161,46 \\
\hline 90 & sup & 151,31 & 16812222,05 & 73096,62 & $\$ 66.152,44$ & $\$ 72,04$ & $10,89 \%$ & 918,32 \\
\hline 120 & sup & 113,87 & 12652222,10 & 55009,66 & $\$ 49.783,74$ & $\$ 96,05$ & $19,29 \%$ & 518,32 \\
\hline 150 & sup & 120,48 & 13386666,53 & 58202,90 & $\$ 52.673,62$ & $\$ 120,06$ & $22,79 \%$ & 438,73 \\
\hline
\end{tabular}

DMC = disposição das mangueiras nos canteiros, sup = superficialmente, sub = subsuperficialmente; PPA = peso do pé de almeirão; PTH = peso total de plantas por hectare; $\mathrm{QM} 230$ = quantidade de maços de 230 gramas; $\mathrm{R}=$ receita; $\mathrm{C}=$ custo com nitrogênio (ureia); $\mathrm{M}=\mathrm{Margem}$ de custo do nitrogênio (ureia) no faturamento total; $\mathrm{EF}=$ eficiência financeira. 
de disposição. Para se realizar a análise financeira, convencionou-se que cada maço de almeirão deveria pesar no máximo $230 \mathrm{~g}$, sendo a quantidade de maços determinada pela massa fresca total de plantas produzidas em um hectare divido pelo peso máximo do maço. O preço médio do maço de almeirão foi de US $\$ 0,905$, de acordo com a cotação do dólar comercial de 24/03/2011 (R $\$ 1,658)$. Considerando-se o espaçamento da cultura do almeirão ser de $0,30 \times 0,30 \mathrm{~m}$, pode-se estimar uma população de $111.111,1$ plantas por hectare.

O aumento da dose de nitrogênio (ureia) gerou maior custo de produção, nas duas formas de disposição das mangueiras nos canteiros. Isso mostra a importância da determinação da eficiência financeira, pois permite a visualização do retorno do investimento, levando em consideração o custo (GITMAN, 2004).

A maior eficiência financeira ocorreu com a dose de $30 \mathrm{~kg} \mathrm{ha}^{-1}$ de $\mathrm{N}$ aplicado nas mangueiras gotejadoras dispostas subsuperficialmente nos canteiros (Figura 2), ou seja, esta é a dose que proporciona maior retorno do investimento para cada dólar gasto. Neste trabalho, a ureia pode ser considerada como custo, mas também como investimento, visto que, para cada US $\$ 1,0$ de ureia investido, obteve-se o retorno de US\$2292,41. Apesar de doses maiores proporcionarem maiores eficiências técnicas (maiores valores de massa fresca e massa seca), provavelmente os produtores estarão utilizando fertilizantes nitrogenados acima do necessário. Portanto, apesar da melhor dose técnica observada ser de aproximadamente $90 \mathrm{~kg} \mathrm{ha}^{-1}$ nas mangueiras gotejadoras dispostas superficialmente nos canteiros, a dose financeira recomendada (por proporcionar uma rentabilidade maior ao produtor) é de $30 \mathrm{~kg} \mathrm{ha}^{-1}$ aplicado tanto superficialmente quanto subsuperficialmente.

\section{CONCLUSÃO}

A forma de disposição das mangueiras afeta a produção da massa fresca do almeirão, com o melhor resultado sendo obtido com a irrigação subsuperficial. A produção e as características agronômicas do almeirão são influenciadas pelas doses de nitrogênio aplicadas na água de irrigação nas duas formas de disposição das mangueiras nos canteiros. A maior eficiência financeira da adubação é obtida com a dose de $30 \mathrm{~kg} \mathrm{ha}^{-1} \mathrm{de} \mathrm{N}$, independente da forma de disposição das mangueiras gotejadoras.

\section{AGRADECIMENTOS}

Agradecemos a Fundação de Apoio ao Desenvolvimento do Ensino, Ciência e Tecnologia do estado de Mato Grosso do Sul (FUNDECT), pela liberação dos recursos para realização dessa pesquisa.

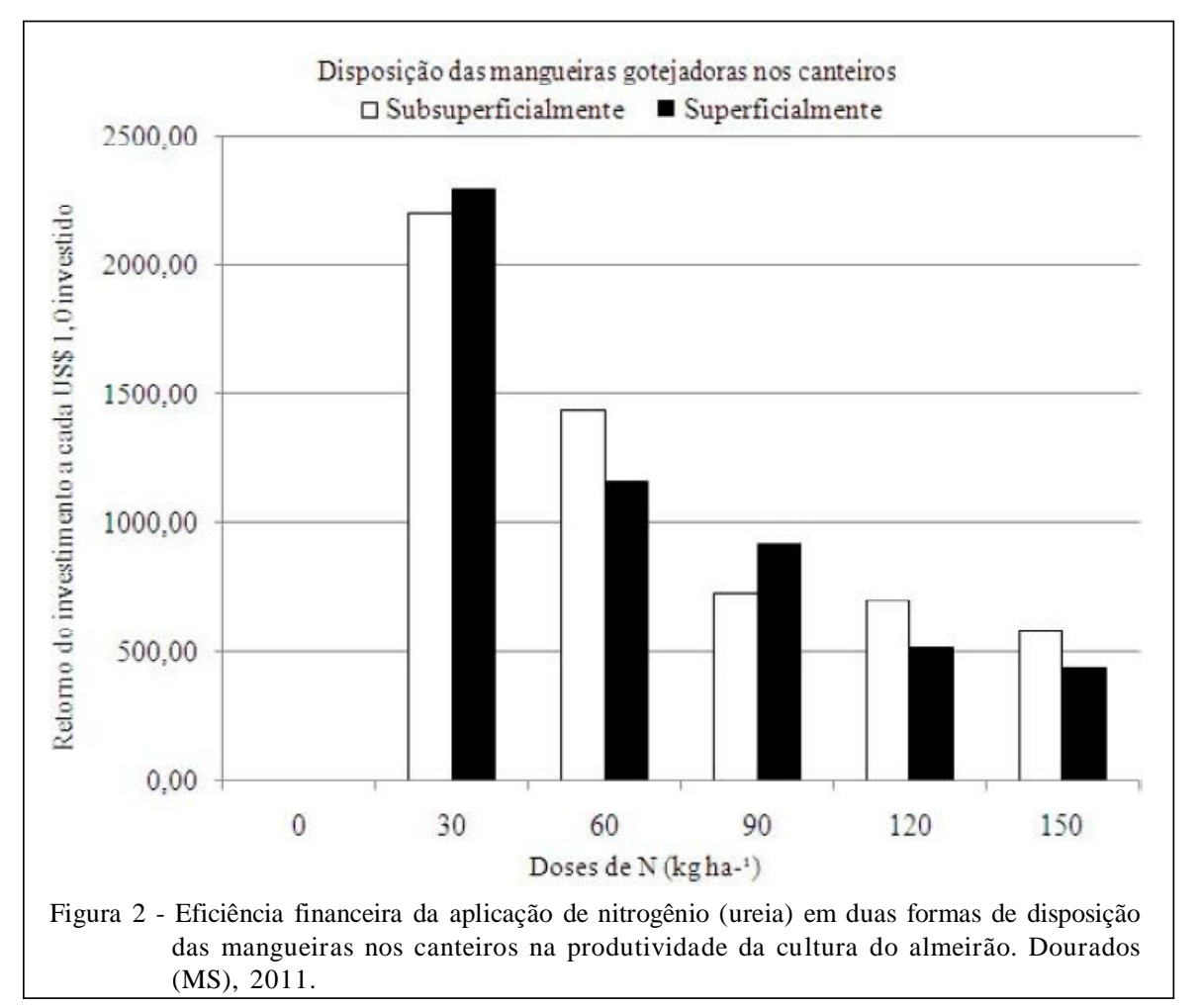

Ciência Rural, v.42, n.10, out, 2012. 


\section{REFERÊNCIAS}

AYARS, J.E. et al. Subsurface drip irrigation of row crops: a review of 15 years of research at the Water Management Research Laboratory. Agricultural Water Management, v.42, p.127, 1999. Disponível em: <http://www.sciencedirect.com/science/ article/pii/S0378377499000256>. Acesso em: 12 nov. 2010. doi: http://dx.doi.org/10.1016/S0378-3774(99)00025-6.

BANZATO, A.; KRONKA, J. Experimentação agrícola. Jaboticabal: FUNEP, 1992. 323p.

BERNARDO, S. et al. Manual de irrigação. 7.ed. Viçosa: UFV, 2005. 611p.

BURT, C. et al. Fertigation. San Luis Obispo: California Polytechnic State University, 1995. 320p.

EMBRAPA. Centro Nacional de Pesquisa de Solos. Sistema brasileiro de classificação de solos. 2.ed. Rio de Janeiro, 2006. 306p.

FILGUEIRA, F.A.R. Novo manual de olericultura: agrotecnologia moderna na produção e comercialização de hortaliças. Viçosa: UFV, 2003. 402p.

GITMAN, L.J. Princípios da administração financeira 10.ed. São Paulo: Prentice-Hall, 2004. 745p.

HAVLIN, J.L. et al. Soil fertility and fertilizers. 7.ed. Upper Saddle River: Pearson Education, 2005. 515p.

HOJI, M. Administração financeira: uma abordagem prática. São Paulo: Atlas, 2007. 525p.

MANTOVANI, J.R. et al. Produção de alface e acúmulo de nitrato em função da adubação nitrogenada. Horticultura Brasileira, v.23, n.3, p.758-762, 2005. Disponível em: <http:/ /www.scielo.br/pdf/hb/v23n3/a14v23n3.pdf>. Acesso em: 06 nov. 2010. doi: http://dx.doi.org/10.1590/S010205362005000300014 .
NOVO, M.C.S.S. et. al. Desempenho de três cultivares de almeirão sob cultivo protegido. Horticultura Brasileira, v.21, n.1, p.8487, 2003. Disponível em: <http://www.scielo.br/ s cielo.php? script $=$ sci_arttext \& pid $=$ S 0102 $05362003000100018 \& \operatorname{lng}=$ en\&nrm=iso>. Acesso em: 27 out. 2010. doi: http://dx.doi.org/10.1590/S0102-05362003000100018.

READ, J.J. et al. Narrow-waveband reflectance for remote estimation of nitrogen status in cotton. Journal of Environmental Quality, v.31, p.1442-1452, 2002. Disponível em: <https://www.agronomy.org/publications/jeq/ abstracts/31/5/1442>. Acesso em: 24 nov. 2010. doi: 10.2134/ jeq2002.1442.

SALVADOR, D.J. et al. Produção e renda bruta de cebolinha e de almeirão, em cultivo solteiro e consorciado. Acta Scientiarum Agronomy, v.26, n.4, p.491-496, 2004. Disponível em: <http://periodicos.uem.br/ojs/index.php/ ActaSciAgron/search/results>. Acesso em: 12 de nov. 2010. doi: $10.4025 /$ actasciagron.v26i4.1811.

SAS Institute Inc. SAS/STAT ${ }^{\circledR}$ 9.2: user's guide. Cary, NC 2008. 252p

SCHRÖDER, J.J. et al. Does the crop or the soil indicate how to save nitrogen in maize production? Reviewing the state of the art. Field Crops Research, v.66, p.151-164, 2000. Disponível em: <http://www.sciencedirect.com/science/article/ pii/S0378429000000721>. Acesso em: 05 nov. 2010. doi: http://dx.doi.org/10.1016/S0378-4290(00)00072-1.

STEINER, F. et al. Acúmulo de nitrato e produção de duas cultivares de almeirão em função da adubação nitrogenada. Global Science and Technology, v.3, n.2, p.60-69, 2010. Disponível em: <http://rioverde.ifgoiano.edu.br/periodicos/ index.php/gst/article/view/145>. Acesso em: 02 dez. 2010

TEIXEIRA, L.A.J. et al. Ganhos de eficiência fertilizante em bananeira sob irrigação e fertirrigação. Revista Brasileira de Fruticultura Jaboticabal, v.33, n.1, p. 272-278, 2011. Disponível em: <http:// www.scielo.br/scielo.php?script $=$ sci_arttext $\&$ pid $=S 0100$ 29452011005000030\&lng=pt\&nrm=iso>. Acesso em: 06 de mar. 2011. doi: 10.1590/S0100-29452011005000030. 